\title{
Is Practical Knowledge Prior to Theoretical Knowledge in Action? Reflecting on Anscombe's Institutional Transparency
}

\section{Veronica Rodriguez-Blanco ${ }^{1}$}

Published online: 1 September 2018

(c) The Author(s) 2018

\section{Introduction}

This paper will expand on Tollefsen's insights into the New Natural Law (NNL) theory as presented in his paper in the present volume. ${ }^{1}$ NLL theorists are committed to the view that basic goods are grasped by reason in opposition to a perspective that engages with human nature. As Tollefsen points out, “The 'New' view is unlike at least some older views that take human nature, or a metaphysics of human nature, to be prior to and necessary for the derivation of moral norms." 2 Thus for the old natural law theorist, moral or ethical normativity is derivative of natural normativity; by contrast, as explained by Tollefsen, the new natural law theorist distinguishes between theoretical and practical reason, and this is to my mind the key distinction between old and new natural law theorists. For the NNL theorist, the practical order is irreducible to the theoretical/metaphysical order and the latter explanation of action is parasitic on the practical order when we act.

Tollefsen's strategy in "Aquinas's Four Orders, Normativity, and Human Nature" is to defend NNL theorists by showing that the goods realized in practical reason are manifested in that order and not in the order of nature. In other words, it is only because the good is intelligible to us, i.e. we can access the good through our reason, that we can engage with it. For Tollefsen this is not a purely epistemic point; it is not simply that we know the good through our intellect but that the manifestation and realization of the good is according to how we understand what the good is in action.

\footnotetext{
1 I am grateful to Gabriele De Anna for his insightful editorial comments and Michael Haskins for improving the style of the original manuscript.

2 Tollefsen, "Aquinas's Four Orders, Normativity, and Human Nature," Journal of Value Inquiry, 52, p. 1 of the original manuscript.
}

Veronica Rodriguez-Blanco

v.rodriguez-blanco@surrey.ac.uk

1 Centre for Law and Philosophy, University of Surrey, Frank Whittle Building, 5th Floor, Guildford GU2 7XH, UK 
In this way, practical reason and the realization of the good is primarily forwardlooking as opposed to theoretical, epistemic or metaphysical approaches which are backward-looking ways of understanding action, i.e. actions in terms of motivations or the pair beliefs/desires that explain the action. ${ }^{3}$

According to Tollefsen two important arguments have been advanced by NNL theorists: a) we cannot infer the good from regularities unless we already know the good, therefore no empirical observation of natural teleology will either help us or be sufficient to understand the complexity of what is good; and b) human goods are plural, complex, incommensurable and open-ended. It would seem that b) is a corollary of a) and therefore we need to understand how practical engagement with the good explains a). The works of Grisez, Finnis, Anscombe, Tollefsen and my own work have engaged with explaining what practical reason is in relation to the good that is caused and brought about through deliberation and choice. In this paper, I will expand on Tollefsen's point concerning the practical reason-focused perspective of the NNL theory and the rejection of the idea that metaphysical/theoretical reason is prior to practical reason by unpacking the underlying meta-ethics of Elizabeth Anscombe in relation to evaluative facts.

I will argue that for Anscombe 1) evaluative facts and natural facts are not separated and 2) when we act and therefore take the practical, first-person or deliberative perspective, we look neither at the natural nor evaluative facts that constitute the background of our actions and social practices. These two insights are key to reinforcing the point that the practical domain is separate from the metaphysical/ theoretical domain of action and social practices when we act.

\section{Anscombe's Institutional Transparency Thesis and the Unity of Intelligibility}

When we act, this is not merely a physical movement or some mental state of a human actor. We experience these phenomena of the physical world in form of a unity that results from the inner dimension of these actions. Or, as we might put it more precisely: this unity results from the agent's choice and intention. The choice that expresses itself in the physical realm in certain movements makes it a certain kind of action or constitutes its nature or species. ${ }^{4}$

If this is the case, then, the question becomes how this inner dimension, which gives form to human action, can be intelligible to third persons. For example, when I see someone sitting at a desk and tracing lines on a sheet of paper with certain features, I understand that she is writing a letter if and only if I grasp what she intends

\footnotetext{
3 See my book Veronica Rodriguez Blanco, Law and Authority under the Guise of the Good (Oxford and Portland, Oregon: Hart Publishing, 2014), chapters 1 and 4. Tollefsen puts this point as follows: "A further consideration is that all truths in the practical domain are true in relation to what is not yet" (Tollefsen, Op. cit., p. 12, original manuscript).

4 In what follows, I develop an arguemt which I had outlined (with Pilar Zambrano) in "One Myth of the Classical Law Theory: Reflecting on the 'Thin' View of Legal Positivism," Ratio Juris 31 (2018): 9-32.
} 
to do. This inner dimension is intelligible because the logos of intentional actionsin other words, the reasons behind the actions — can be understood through the specific social context in which the exterior performance occurs. I understand her intentions, in the example, since I recognize objects with the typical features of stationary and envelops on the desk of the agent and since I know what is required by the practice of writing letters.

Anscombe discusses this relationship between the exterior performance of actions and the institutional facts or social contexts in which they occur in her 1958 article "On Brute Facts." In what I have termed her institutional transparency thesis, Anscombe argues that while a factual description of an action "A" is not a description of the institution behind "A," the existence of a factual description of action "A" does presuppose an institution A. Put in the context of intelligibility, to understand the inner dimension (i.e., intention, choice) of a third person's actions requires understanding the social or institutional context in which those actions occur. To understand that the utterance of certain words by someone is a promise, for example, I need to know how promises are institutionalized in my community, even if - and this is the transparency thesis - I do not need to think about that while I promise or when I recognize a promise. Furthermore, the intelligibility of these actions occurs not at the level of the theoretical but at the level of the practical.

To explain further, we must ask what the institution behind the description is. Anscombe offers an example, "I Owe the Grocer Five Pounds for the Potatoes that the Grocer Has Supplies to Me", that we can use as a starting point.

Let us say that I order a kilogram of potatoes from the grocer, the grocer loads the potatoes into his delivery van, the grocer rings my doorbell, he unloads the potatoes from his delivery van, and he gives me a bill for five pounds.

You are present at my house during this time and so you observe both my actions and the grocer's actions. You conclude, as an observer, "I owe the grocer five pounds." You reach this conclusion, but how? Do you reach this conclusion because you ask me what am I doing and I tell you? But you would only ask this question when what I am doing is unintelligible to you. You understand both the way I move my body and the reasons why I am moving my body as a unity. Unless you already possess the concepts necessary to understand the reasons why I move my body-concepts such as supplying, owing, and five pounds - simply observing the way the grocer and I move our bodies as I receive the potatoes and the bill for five pounds does not tell you that "I owe the grocer five pounds for the potatoes he has supplied." You only understand the obligation of owing, the obligation only becomes intelligible to you, if you already understand the action of supplying as the reason for the obligation of owing. In that case, you already grasped concepts such as supplying, owing, and five pounds prior to the bodily movements between the grocer and me. You, the grocer, and myself had previously learned that set of concepts within the context of the social institution of buying and selling. We learned that set of concepts when we were young and learned that the exchange of goods

\footnotetext{
5 Elizabeth Anscombe, "Brute Facts", Analysis 18 (1958): 69-72.

6 Ibid., p. 72.
} 
in our society creates obligations. We learned as a unity the bodily movements and the reasons why we buy, sell, and satisfy our obligations in the exchange of goods. My bodily movements, the bodily movements of the grocer, and the reasons why we perform those actions, in other words the logos of those actions, are understood as a whole in Anscombe's example. Your grasp, as an observer, of the unity of the bodily movements and reasons why those bodily movements were performed does not describe the institution of buying and selling. Rather, this background institution provides you with the basis by which you determine the intentions behind the bodily movements that stamp a logos in those bodily movements.

Because the action is practical, it should be understood as practical. We can say that the action is practical because it is about the intentions of the grocer and the buyer. The grocer and buyer intend to produce a certain state of affairs and they know why they are doing what they are doing. The grocer knows why he loads a kilogram of potatoes into his delivery van, why he rings the doorbell, and why he unloads the potatoes at the buyer's house. As the buyer, I know why I am ordering the kilogram of potatoes, why I am receiving them from the grocer, and why I am receiving the bill for five pounds. Additionally, we both know what the other is doing and why they are doing it because we both understand the background institution of buying and selling that allows us to make our bodily movements intelligible.

Would, Anscombe asks, the same bodily movements in a film where one actor supplies the potatoes and another actor receives the potatoes be different from the example above? ${ }^{7}$ In the example above, as the buyer, I owe the grocer five pounds, whereas in the film we would not say that the actor playing the buyer owes the actor playing the grocer five pounds because the intention of the agents is different. Despite the actors' bodily movements in the film, they do not intend to create a purchasing contract or the obligation to satisfy such a contract. When the grocer hands me the bill in the example in which I am the buyer, the grocer and I do intend to create such a contract; therefore, I understand that I owe the grocer five pounds. And the observer, who understands the difference between the background institutions in each situation, understands the difference between those two situations.

\section{The Intelligibility of Intentional Action: One Action with Two Perspectives}

To further understand this subtle and difficult point we need to understand Anscombe's conception of intentional action which rejects actions as a two-link causaleffect chain composed of an interior act, i.e. mental states such as beliefs and desires that cause an action, and the exterior action that is the effect of the interior act. Like Aquinas, Anscombe does not separate the physical action and the answer to the question why the agent is acting in the way he or she is acting. If the question why cannot be applied to the physical action, then more than likely the action was not intentional. Which is to say that there are not two actions, an interior and an exterior,

\footnotetext{
${ }^{7}$ Ibid., p. 70.
} 
but only one action. Different perspectives can analyze that action, but the exterior action is one and the same as, and not essentially different from, the interior will. The one action is its performance and manifestation. ${ }^{8}$

What, then, is the choice or will that is performed and manifested by the exterior action? To answer, we must determine whether or not a distinction exists between the intention to act, in which case my will is operant and involved in the action, and a voluntary action. Of course, actions can be voluntary; for example, talking, walking, jumping, etc. are voluntary actions. Actions can also be involuntary; for example, my lungs' respiratory functions, my stomach moving, etc. are involuntary actions. But for voluntary actions specifically, do all voluntary actions involve the will? Put more concretely, do all voluntary actions involve a choice? ${ }^{9}$

Consider two different examples. In one, I move my arm but instead of my arm moving my foot moves. In another, I move my arm and my arm in fact moves. My actions are voluntary in both examples; however, my action does not perform my choice in the first example. My choice is to move my arm, and in this first example my choice is not satisfied. If you were observing me in these two instances, you would observe my foot move and then you would observe my arm move. How would you be able to determine whether or not my choice was satisfied in each instance? We can make a distinction, then, between a merely volitional act, i.e. an act initiated by a person, and a willful act, i.e. a volitional act that actually performs their choice. That said, how could third-person observers know whether the act is volitional or willful? Observers could see that I move my foot and arm, but they cannot know my choice so they cannot, from observation alone, know that my arm moved intentionally.

Arguably, the way to determine whether or not an action is willed is to ask the agent to describe the action. For example, we see John moving his hand and hitting Mark, and we ask John whether his motion - which was clearly volitional - was intended to hit Mark or whether the hitting was accidental. But, even if the agent's description is the best way of determining whether or not the action is willed, agents are only very rarely asked to describe their actions because, in most cases, the institutional background in combination with the physical movements of the action are sufficient to make such a determination. If John hits Mark while they are standing on a ring in shorts and wearing boxing gloves, we know that the hitting was intended. The agent's description of her choices may even become irrelevant, as in the context of the law, where the institutional background that makes these choices intelligible.

\footnotetext{
8 See Aquinas, Suma Theologiae I-II, qq. 17-20, especially q. 17, a. 4; qq. 18 a.6 and q. 20.

9 See Ibid., I-II, q. 18, particularly, aa. 2 and 7; John Finnis, Moral Absolutes. Tradition, Revision and Truth (Washington D.C.: The Catholic University of America Press, 1988), pp. 65-66; and Martin Rhonheimer, Perspective of the Acting Person: Essays in the Renewal of Thomistic Moral Philosophy (Washington D.C: Catholic University of America Press, 2008), p. 41.
} 


\section{Davidson and Hume}

A theoretical engagement with human action is closer to an explanation than to a form of understanding. In theoretical or metaphysical knowledge, actions are individuated through a cognitive process that focuses not on identifying choices performed in actions but on identifying actions as effects of previous events. Donald Davidson, in his account of intentional action, defends this causal theory of action and the correlative theory of the interpretation of concrete actions. ${ }^{10}$

Many scholars have assumed that Davidson and Anscombe hold similar views regarding intentional action because Davidson uses some of Anscombe's ideas and because of the difficultness of Anscombe's work, which does not rely on a general theory or system. ${ }^{11}$ However, Anscombe's and Davidson's accounts of intentional action and of the interpretation of action are, in fact, fundamentally different.

For Davidson, intentional actions are understood in terms of the reasons that the agent gives when describing what the agent did. The goal is to rationalize the action. Furthermore, the agent can be said to have a reason if a) the agent has a proattitude toward the action and $b$ ) the agent believes (or knows, remembers, notices, perceives) that his action is of that kind. ${ }^{12}$ Davidson calls this pairing of belief and desire a primary reason and he claims that "a primary reason for an action is its cause." 13

In Davidson's account, beliefs and desires are mental events that (may) cause an exterior action, which is a subsequent and corresponding event. The relationship between mental events and actions is causal, specifically a kind of causal relationship between facts. ${ }^{14}$ So, my desire to flip a switch and my belief that my action is of that kind causes the action I flip the switch. Furthermore, observation of the action allows us to induce the cause. Even though we only observe the effect, i.e. the action, which in this case is the flipping of the switch, we can induce the cause, i.e. the mental events that caused the effect. This cognitive process, which allows us to individuate the nature of various actions, is not fundamentally different from the cognitive process which explains physical events.

Davidson denies that there are psychophysical laws that connect actions and reasons, saying that if there are laws they ought to be neurological, chemical or physical. ${ }^{15}$ In the last forty years, his account of intentional action has exerted great influence. In that time, practical reasoning has tended to be assimilated into intentional action as a mental state. ${ }^{16}$ The assimilation of practical reasoning as a mental state offers two advantages over competing accounts like Anscombe's. One, this

\footnotetext{
10 Donals Davidson, “Actions, Reasons and Causes," Journal of Philosophy 60 (1963): 685-700.

11 See Julia Annas, "Davidson and Anscombe on the 'same action"”, Mind 85 (1976); 251-257.

12 Davidson, op. cit., p. 685.

13 Ibid.

14 Ibid.

15 Ibid.

16 See, for example, Jay Wallace, "Practical Reason," Stanford Encyclopaedia of Philosophy (http://plato .stanford.edu/): "Practical reasoning gives rise not to bodily movements per se, but to intentional actions, and these are intelligible as such only to the extent they reflect our mental states."
} 
assimilation allows neo-Humeans ${ }^{17}$ to advance the Humean view that desires or proattitudes motivate and explain intentional actions. Two, this assimilation is compatible with a descriptive, scientifically-neutral understanding of action as caused by mental events. Despite these advantages, Davidson's view contains a notable flaw; namely, it has no way to guarantee that the causal link between a reason and the corresponding action is right. ${ }^{18}$

There are other problems that affect the standard model of intentional action. If an intention to act is a mental state it entails that I can remember my mental state; that I can reflect on it, but it seems that the memory of or reflection on my intention as a mental state vanish. If intentions are purely mental states they can vanish, we might not remember them correctly, they might not endure, and then our intentional action might also vanish.

In conclusion, putting human actions on the same level as the physical / theoretical or metaphysical events, or putting the understanding human actions on the same level as the explanation of causal relationships, fails to guarantee the individuation of actions.

As previously discussed, the best way to determine if an agent willed an action is to ask the agent him or herself for a description of the action. We can prompt a description of the action by asking the agent why he or she performed an action. ${ }^{19}$ Prompting a description in this way is known as the why-question methodology and is the key method in Anscombe's Intention for clarifying the connections between the action and (our) practical reasoning. ${ }^{20}$ Fully understanding this methodology requires accounting for several considerations:

a) paradigmatically, an intentional action is a sequence of actions with aim toward the action's final end.

b) we know that the explanation finishes because the last step is described in terms of good-making characteristics that make intelligible and illuminate as a coherent whole the successive steps of the action.

\footnotetext{
${ }^{17}$ See Gilbert Harman, Change in View (Cambridge, Mass.: MIT Press, 1986); Gilbert Harman, 'Willing and Intending,' in R. Grandy and R. Warner, eds., Philosophical Grounds of Rationality (New York: OUP, 1986); Simon Blackburn, Ruling Passions (Oxford: Clarendon Press, 1998); Michael Smith, The Moral Problem (Oxford: Blackwell, 1994).

${ }^{18}$ Roderick Chisholm was the first scholar to write about deviant causal chins in R. Chisholm, "Freedom and Action," in K. Lehrer, ed., Freedom and Determinism (New York: Random House, 1976), p. 28. Other, more radical scholars go further and deny that intentional actions are causes, see for example, Jonathan Dancy, Practical Reality (Oxford: Oxford University Press, 2000).

${ }^{19}$ Moran and Stone offer the following explanation for the why-question methodology: "Hence all psychic forms are performance modifiers: insofar as they are employable in action-explaining answers to the question 'why?', they express forms of being on-the-way-to-but-not-yet having $\Phi$-ed, of already stretching oneself toward this end". See R. Moran, and M. Stone, "Anscombe on Expression of Intention," in C. Sandis, ed., New Essays in the Explanation of Action (New York: Palgrave MacMillan, 2009), p. 148.

${ }^{20}$ Anscombe's exposition follows Aquinas's explanation of intentional action very closely. Notably, Anthony Kenny, Aristotle's Theory of the Will (New Haven: Yale University Press, 1979) argues that Aquinas' model would be better understood more as a Gestalt psychology.
} 
c) we have only one action, not different actions, and that one action is unified by the action's final end as a reason for the action, understood with regard to goodmaking characteristics.

d) the reason must be a reason that might be genuinely offered to others as a justification, and this reason must also be the same as the reason that the agent gives to him or herself.

With these considerations in mind, we can now explain the why-question methodology.

Anscombe begins Intention by stating that the subject of the book should be studied under three headings: expression of an intention; intentional action; and intention in acting, ${ }^{21}$ and that all these should be understood as interdependent. Thus, an expression of an intention cannot be understood as a prediction about my future acts nor as an introspective explanation of an intention such as desires, wants, etc. If I utter "this afternoon I will go for a walk" as an expression of an intention, the utterance cannot be understood as a forecast. Indeed, the intention is rightly expressed by the utterance, even if then it turns out that as a forecast it would have been false, since a friend comes to visit and I cannot leave home. The utterance cannot either be an expression of desires or wants. I might intend to walk even if I have no desire whatsoever to do it: for example, I might have to go to my friends and give him back the book he lend me, even if I would rather do something else. Anscombe tells us, however, that people formulate expressions of intentions that are about the future and that they turn out to be correct. ${ }^{22}$ How is this possible?

In order to answer this question, she tries to explain the way in which we can identify intentional acts and separate them from non-intentional actions. To do so requires taking the logical step of trying to understand what it means when I say that I have acted with an intention. For Anscombe, acting intentionally means acting for a reason or being able to provide reasons for actions, with the understanding that the question why can be said to apply to such actions. ${ }^{23}$ All of which is to say that we act intentionally when we act for reasons, which in turn entails us to be responsive and sensitive to a framework of justification for our actions. If I perform an action $\Phi$; am asked why; and give a genuine answer, for example, "I was not aware I was doing $\Phi$ " or "I did not know I was performing $\Phi$," the action cannot be said to be intentional or directed by reasons. The action might be voluntary, but it is not intentional. ${ }^{24}$ On the other hand, if the answer takes one of these forms: "because $\Phi$ " or "in order to $\Phi$," then it might be a prima facie case for an intentional action, which is to say an action directed by reasons. Reasons demonstrate themselves, so to speak, in intentional actions, and reasons demonstrate that they operate as a part of the practical reasoning of an agent.

\footnotetext{
${ }^{21}$ Moran and Stone explain the transformation of these three headings in the post-Intention literature, see op. cit., p. 137.

${ }^{22}$ Elizabeth Anscombe, Intention (Oxford: Blackwell, 1957; 2nd Edition, 1963), paragraphs 3-4.

${ }^{23}$ Ibid., paragraphs 4-6.

${ }^{24}$ Ibid., paragraph 17.
} 
The problem for the understanding of action is whether or not, when asked why we performed that action, we can exert control over the truthfulness of the response we give in answer. A further problem presents itself: whether or not we can give a plausible answer without reliance on the testimony of the agent of the action.

Anscombe notes that a set of contextual conditions allow us to determine whether or not the agent has given his or her genuine intentions in response to the question $w h y .{ }^{25}$ This set of contextual conditions are those concepts learned at a young age through social context. For example, we learn that money is necessary to purchase goods and that if we order goods for home delivery then we owe the seller money. Given our example of a scene in a film in which a grocer delivers potatoes, we know from the contextual conditions that when the actor-buyer says that he owes the actorgrocer five pounds, the actor-buyer's words are not genuine. Or given the example from Anscombe's Intention, if a person poisons a river with toxic waste and we ask "why?", and the person answers "I am just doing my job," then we can determine whether or not this action is in fact a part of his job and whether or not the contextual conditions make it true, and, if not, then we have a reason to suspect that his response is not genuine.

Intentional actors, or actions performed for reasons, require a sequence of steps or actions and, therefore, a sequence of reasons that explain each action-step. If one writes a letter and has a reason to do it (e.g., greet a friend), she writes it by taking a sheet of paper and a pen and by tracing signs with the pen on the paper. Writing the letter is her reason to trace lines on the sheet and scribbling on the sheet is her reason for taking the sheet from the drawer. This being the case, the question arises, then, of how we can know when the explanation is complete and the agent can stop. Anscombe argues that the justification stops when the agent describes the endpoint of the action with regard to what is desirable or good for itself. The endpoint of the action is, then, a state of affairs, a fact, an object, or an event that the agent appears to consider desirable or good. The state of affairs, fact, object, or event is considered by the agent to be a good sort of thing. This explanation is commonsensical and arguably the most naive explanation of our actions. ${ }^{26}$ For example, when the potatoes are delivered to my house, the grocer does not say he is delivering them because he is in the mental state of desiring to deliver potatoes and has the mental state of believing and remembering that this is that kind of action. On the contrary, in order to deliver the potatoes the grocer loads the potatoes into his delivery van, drives to my house, parks the van in front of my house, exits his van, unloads the potatoes from the van, rings my doorbell, and takes the potatoes to my kitchen. The sequence of action steps obtain intelligibility and unity in the good-making reason that, for instance, the grocer sells potatoes that he buys from farmers, that he wants to earn money, etc.

Let us recall the difference with the actors in the film scene buying and selling potatoes. From the point of view of the agents it was their intention to attain a

\footnotetext{
25 Ibid., paragraph 25.

26 See Germain Grisez, "The First Principles of Practical Reasons: A Commentary on the Suma Theologiae, 1-2, Question 94, Article 2," Natural Law Forum 10 (1967), p. 177.
} 
specific good that makes the distinction between the actions of the actors in the film and the actions of the grocer who delivered the potatoes to my home. In the film scene buying and selling potatoes, the actors do not intend to buy and sell potatoes, therefore we cannot say that the actor-buyer owes five pounds to the actor-grocer.

To return to our initial discussion, how can the intention/choice of the agent become intelligible to an observer and allow the observer to individuate that intention/choice? Intelligibility requires i) that both the agent and observer hold a mutual understanding of what good-making characteristics may be intended or chosen by the agent in performing an action, and ii) that the good-making characteristics intended by the agent are manifest in the action. The first condition requires that the good making characteristics do not exist by pure convention or exist just given in nature, but are, at least to some extent, objects of human intelligence. Were the good-making characteristics not objects of human intelligence, the agent would not even be able to name them. The second condition requires that the intended goodmaking characteristics of an action be a specific instance of the good-making characteristics of the institutional background or social practices that give actions their final form or $\log o$ s. $^{27}$

These conditions in mind, the primary aim of the why-question methodology is to highlight the articulation or structure of an intentional action. ${ }^{28}$ In our potatoes example, the grocer does not think and reflect on why he is doing what he is doing at each concrete action step. Rather, the grocer understood the sequence of action steps necessary for buying and selling and the good-making characteristics that explain why we human beings buy and sell in the social context.

The concern, then, is not to discover the propositional attitudes-the desires and beliefs that explain the buying and selling-nor even to explicitly describe the institution of buying and selling, nor to discover the nature of the human action in terms of a given good. The concern is to understand whether or not the action is intentional and to understand what choice the agent intends in the performance of the action. Putting the testimony of the agent aside for the moment, it is only possible to understand the agent's choice when his action is understood as a specific instance within a social practice and justified by the good-making characteristics of that social practice. Only once those understandings are in place can the observer grasp the intentional action as a unity of physical movements and the answer to the question why, or the grounding logos of the action.

\footnotetext{
${ }^{27}$ See Ibid., 174. These arguments are further developed in P. Zambrano, "Fundamental Principles, Realist Semantics and Human Action," Recthstheorie, 46 (2015), pp. 330 ss.

${ }^{28}$ Candace Vogler, C. "Anscombe on Practical Inference," in E. Millgram, ed., Varieties of Practical Reasoning (Cambridge, Mass.: MIT University Press, 2001).
} 


\section{Conclusion}

Tollefsen has said that, "traditional Thomists and some contemporary naturalists treat morality as a matter of the first order: morality's norms are to be found in natural norms. Why, they might ask, is that an error?"29 Tollefsen argues that just because something has natural good characteristics, it does not necessarily have a motivational grip on us and, worse, does not reflect the complexity, plurality, incommensurability and open-ended features of human goods as opposed to the good of natural kinds (like oak trees). I, however, tackle the question of whether the practical domain is prior to theoretical knowledge in action in a different way.

If Anscombe is correct about the importance of institutional facts and in saying they are inevitably transparent to us, then we learn the logos or order of reasons in action implicit in the practical domain with other human beings, in our interactions with other human beings and in our social and institutional practices. We also acquire complex, incommensurable, plural and open-ended human goods. This knowledge is practical because it is directed to action. It is flawed, as Tollefsen and NNL theorists have emphasized, to say that the good first requires theoretical reflection and/or knowledge about nature and/or human nature, and thereafter practical grip mysteriously emerges. These accounts leave unexplained how volition, motivation or will are added to our theoretical knowledge or knowledge of human nature. Rather knowledge of the good is practical all the way through, for instance, when we learn words like "owe," "promise" or "obligation," and these words and actions entail and partially depend on theoretical knowledge, e.g. when I promise to make you a cup of tea and know that I have to heat the water to the boiling point but that, if I am not careful, the boiling water will scald me. But this knowledge about nature and human nature is learned towards action and therefore towards ends that will be realized in the practical domain. When I am acting, I am not in the contemplative or theoretical mode, connecting my ideas, beliefs and representations about the world with reality. On the contrary, I am engaging in transforming the world and bringing about something through my actions from making a cup of tea, to writing musical pieces or novels, to buying potatoes.

Open Access This article is distributed under the terms of the Creative Commons Attribution 4.0 International License (http://creativecommons.org/licenses/by/4.0/), which permits unrestricted use, distribution, and reproduction in any medium, provided you give appropriate credit to the original author(s) and the source, provide a link to the Creative Commons license, and indicate if changes were made.

${ }^{29}$ Tollefsen, Op. cit., p. 7 manuscript. 